\title{
Instantaneous p-q Power Theory for Control of Compensators in Micro-Grids
}

\author{
E. H. Watanabe ${ }^{1}$, Senior Member, IEEE, J. L. Afonso ${ }^{2}$, Member, IEEE, J. G. Pinto ${ }^{2}$, Student Member, IEEE, \\ L. F. C. Monteiro ${ }^{3}$, Member, IEEE, M. Aredes ${ }^{1,4}$, Member, IEEE and H. Akagi ${ }^{5}$, Fellow, IEEE \\ ${ }^{1}$ COPPE/UFRJ - Electrical Eng. Department, 21941-972, Rio de Janeiro, Brazil \\ ${ }^{2}$ University of Minho, Industrial Electronics Department, 4800-058, Guimarães, Portugal \\ ${ }^{3}$ PROQUALI, Estrada do Galeão 2730 / 201, Ilha do Governador - 21931-582, Rio de Janeiro, Brazil \\ ${ }^{4}$ POLI/UFRJ - Electrical Eng. Department, 21941-972, Rio de Janeiro, Brazil \\ ${ }^{5}$ Department of Electrical and Electronic Engineering, Tokyo Institute of Technology, Tokyo 152-8550, Japan
}

\begin{abstract}
The main objective of this tutorial is to present the basic concepts on the instantaneous $p$-q Theory and them show its applicability for controlling switching converters connected in a micro-grid. These converters can be used for connecting renewable energy sources (solar, wind, and others) to the microgrids or for harmonic, reactive power or unbalance compensation, and even for voltage regulation. The emphasis is given on the compensation characteristics derived from the $p-q$ Theory, and simulation results of test cases are shown. Special attention is put on the oscillating component of the instantaneous real power, as it may produce torque oscillations or frequency variations in weak systems (micro-grids) generators. This oscillating component, as defined in the $p-q$ Theory, gives the amount of oscillating energy between the source and the load, and its compensation through a switching compensator must have an energy storage element to exchange it with the load. With the $p-q$ Theory the energy storage element can be easily calculated as a function of the average component of the instantaneous real power, which depends on the observation period.
\end{abstract}

Keyword - p-q Theory, instantaneous power, active filter, power conditioner, micro-grids, weak electrical systems

\section{INTRODUCTION}

This paper presents a tutorial, including well-known and previously published texts, as well as some new material.

Compensation algorithms for switching compensators are one of the topics that have been exploited, exhaustively, by power electronics engineers over the last almost 30 years. These compensation algorithms are derived from electric power theories that are defined in the frequency domain or in the time domain.

The conventional active $(\mathrm{P})$, reactive $(\mathrm{Q})$ and apparent (S) powers, defined in the frequency domain [1]-[3], originally in single-phase circuits and them expanded for three-phase circuits, and several other power quality indices that are derived from them are precise only for off-line calculation and analysis of power quality issues. In general, power definitions in the time domain offer a more appropriate basis for the use in controllers for power electronic devices, because they are also valid during transients. This is especially true if the definitions are done considering already a three-phase circuit instead of considering single-phase circuits and them summing up to have a three-phase system.

In 1983 Akagi, Kanazawa and Nabae proposed a timedomain power theory for three-phase circuit for the control of active filters connected to three-phase three-wire systems, including some notes for four-wire systems [4]. Based on this theory, known today as p-q Theory, other control strategies for active power line conditioners were derived in various publications [5]-[12], including its extension for the use in three-phase four-wire systems. A summary of these applications can be found in [5]. This introduction has some overlap with [5] with the objective to make easier for the attendees to follow the tutorial. References [6]-[7] also have some overlap with this tutorial.

The $p-q$ Theory is valid for any three-phase circuit conditions, and has the advantage of instantaneously separating homopolar (zero-sequence) from nonhomopolar (positive- and negative-sequence) components, which may be present in the instantaneous three-phase four-wire voltages and currents. Indeed, since their instantaneous powers are defined in the $\alpha-\beta-0$ reference frame (Clarke Transformation), it is possible to extract, independently, the homopolar (zero-sequence) component. The p-q Theory also allows a comprehensible explanation as to why imaginary power can be compensated without the need of energy storage elements [5]-[15]. Besides, it also allows determining the amount of energy that must be stored in a compensation device, in order to compensate real oscillating powers that are exchanged between source and loads [8]-[10]. Furthermore, the p-q Theory allows two compensation strategies: constant power at source and sinusoidal currents at source (using the fundamental positive-sequence components of voltage in the control algorithm) [15]. In the case of converters to connect power sources to the grid [16], it can also be controlled to operate with constant power or sinusoidal current injection.

In the literature it can be found other power definitions defined in the time domain. The most important are the FBD (Fryze - Buchholz - Depenbrock) proposed by Depenbrock [17], the CPT (Conservative Power Theory) proposed by Tenti [18], and the CPC (Current's Physical Components) proposed by Czarnecki [19][20]. Also in the literature we can find $\mathrm{p}-\mathrm{q}$ Theory inspired control algorithms for switching compensators as, for example, the p-q-r Theory [21][22][23], which is also defined in the $\alpha-\beta-0$ reference frame. A comparison involving the $\mathrm{p}-\mathrm{q}-\mathrm{r}$ and the $p-q$ Theories is provided in [23]. The control algorithm denominated as Synchronous Reference Frame (SRF) [24] also presents similar aspects related with the p$\mathrm{q}-\mathrm{r}$ and the $\mathrm{p}-\mathrm{q}$ Theories. The SRF control algorithm is 
defined in the $d-q-0$ reference frame. All of these control algorithms can be applied to control switching compensators connected in three-phase systems, with or without neutral wire.

Control algorithms derived from the $\mathrm{p}-\mathrm{q}$ Theory have been widely applied to control switching compensators, and their control algorithms, are well established in the electrical engineering community involved in switching compensators design [5]. However, unfortunately, misinterpretations of the $p$-q Theory still occur when it is considered as a power theory [19]. It occurs when the real and imaginary currents, derived from the $\mathrm{p}-\mathrm{q}$ Theory, are directly compared with the active and non-active currents defined by Fryze in 1932 [28]. As described in [7], these current components can only be compared if certain constraints are respected.

In order to elucidate the aspects that still result in misinterpretations of the $\mathrm{p}-\mathrm{q}$ Theory as a power theory, this paper for the tutorial exploits its power properties for threephase electrical systems, with or without neutral wire, with emphasis on power conditioners (switching compensators) in micro-grids, which generally are weak systems, and where active power oscillations may have to be compensated by using a short-term energy storage system.

In fact, in a micro-grid, oscillating active power may appear due to variations in the load consumption or fluctuation in the renewable energy sources generation. Van der Hoven [25] presents a long published report on the frequency variation range of the wind speed and in [26] it is shown that most micro-grids have torsional torque oscillation that should be damped to avoid frequency variation. Suvire [27] analyzed problems due to power fluctuations given by wind generators connected to weak systems. As a solution he proposed the use of flywheel as energy storage system and a converter to mitigate the problems due to power oscillations.

This tutorial paper is structured as follows. In section II the p-q Theory is presented, including the physical meaning of real and imaginary powers, including their average and oscillating components. In sequence, section III presents a control algorithm, based on the $\mathrm{p}-\mathrm{q}$ Theory, for switching compensators connected in shunt with a three-phase threewire power grid. The features provided to the switching compensator, when the p-q Theory is applied, are discussed and some simulation results are also shown. Section IV presents simulation results involving the use of the p-q Theory to compensate for current harmonics, power factor and unbalanced loads. Compensation of power oscillations due to load and/or generation variation in a micro-grid is also done to help the frequency control. Finally, in section $\mathrm{V}$, the major conclusions obtained through this work and suggestions for further works are presented.

\section{BACKGROUND OF THE $\mathrm{p}-\mathrm{q}$ THEORY}

The instantaneous real and imaginary power theory ( $\mathrm{p}-\mathrm{q}$ Theory) is based on the Clarke transformation of threephase voltages and currents into $\alpha-\beta-0$ coordinates. The Clarke transformation of three-phase voltages and currents are given by:

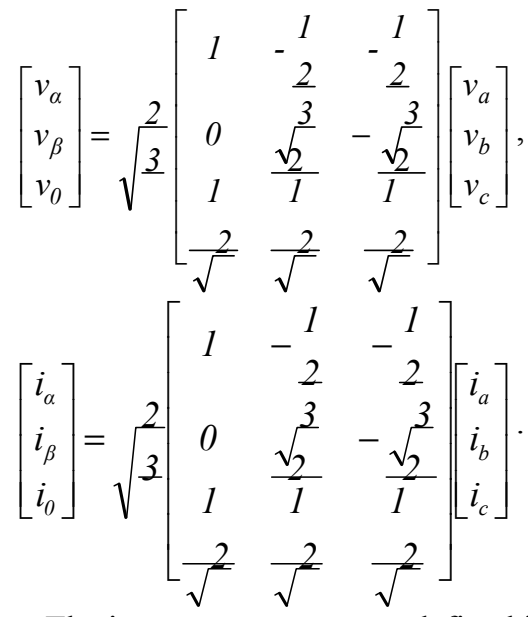

The instantaneous powers defined in the $\alpha-\beta-0$ reference frame are the real power $(p)$, the imaginary power $(q)$ and the zero-sequence power $\left(p_{0}\right)$ given by:

$$
\left\{\begin{array}{l}
p=v_{\alpha} \cdot i_{\alpha}+v_{\beta} \cdot i_{\beta}=\underline{p}+\widetilde{p} \\
q=v_{\beta} \cdot i_{\alpha}-v_{\alpha} \cdot i_{\beta}=\underline{q}+\widetilde{q} \\
p_{0}=v_{0} \cdot i_{0}=\underline{p}_{0}+\tilde{p}_{0}
\end{array},\right.
$$

where, "-" represents the average and " $\sim$ " represents the oscillating components of each power. The average components can be extracted through low-pass filter, as it can be noted in several control algorithms for switching compensators [29]-[33]. It is worth to notice that, generally, the average components are calculated by considering the period of the line frequency as the time reference, but depending on the power system, $1 / 6,1 / 3$ or $1 / 2$ of the period can be used [14]. Indeed, if the load corresponds to a six-pulse rectifier operating in steady state, for example, the average component can be determined using a low-pass filter with a time interval equal to $1 / 6$ of the grid frequency period. However, as it is shown in [9][10], depending on the application, the period for the calculation of the average value may be much higher than the period of the line frequency. In micro-grids applications the problem of load and/or generation variations will certainly require an averaging period greater than the grid frequency period.

It is important to point out that differently from other power definitions, the powers defined in (3) considers all three-phase voltages and currents. In theories presented in [17], [18] and [19][20], the definitions are based on singlephase voltage and current and therefore do not allow the understanding of what is possible to have with definitions in three-phases voltages and currents as in the p-q Theory.

In sequence, the physical meanings of the instantaneous powers defined in the $\alpha-\beta-0$ reference frame, including their average and oscillating components, are explained.

The instantaneous real power $(p)$ represents the energy, per time unity, that flows from the source to the load (or from the load to the source, if negative) through the threephase wires [5][13]. The average component of the real power $(p)$, if positive, constitutes the energy, per time unity, that is transferred from the source to the load. The oscillating component $(\tilde{p})$ corresponds to the energy, per time unit, that is exchanged between the source and the load. Of course, the average value of $\widetilde{p}$ is zero, but at each time instant it represents a quantity of energy flowing in the 
three-phase circuit, and that gives origin to undesirable currents.

The instantaneous real power $(p)$ represents the energy, per time unity, that flows from the source to the load (or from the load to the source, if negative) through the threephase wires [5][13]. The average component of the real power $(\bar{p})$, if positive, constitutes the energy, per time unity, that is transferred from the source to the load. The oscillating component $(\tilde{p})$ corresponds to the energy, per time unit, that is exchanged between the source and the load. Of course, the average value of the oscillating component is zero, but at each time instant it represents a quantity of energy flowing in the three-phase circuit, and that gives origin to undesirable currents.

Conventionally, $\bar{p}$ is calculated considering the line frequency period, and the oscillating component $\tilde{p}$ are due to frequencies components higher than the grid frequency or due to the negative-sequence component. In microgrids, where different kinds of low-inertia or nondispatchable generators (like wind generators) may be connected, $\widetilde{p}$ may appear due to harmonic frequencies, which can be dealt conventionally. However, frequencies lower than the line frequency may be present, and the lack of inertia in the system may produce oscillation in the instantaneous real power, which can also be considered as $\tilde{p}$. For example, if a wind generator is considered, as the wind speed varies along the time, the generated power using maximum power tracking also varies along the time with a period given by the wind speed variation period (if it is periodic), or it may vary randomly. According to Van der Hoven [25] the harmonic spectrum of the wind speed contains frequency components in the range up to $0.017 \mathrm{~Hz}$ (period around 1 minute). This would force the appearance of very low frequency real and imaginary power oscillations in systems with wind generators. Depending on the frequency of $\widetilde{p}$, other generators in the micro-grid can respond and compensate for this variation. However, for some variation frequencies these generators cannot follow and the system frequency may vary.

In three-phase electrical circuits (with or without neutral wire) where voltages and currents are only comprised by their fundamental positive-sequence components, the energy transfer is unidirectional, normally from the source to the load. In this case, the instantaneous real power $(p)$ contains only an average component. There are also others particular situations in which energy can present a unidirectional transfer from the source to the load as, for example, when voltages and currents present the same harmonic components and, moreover, present the same symmetrical components (positive-sequence or negativesequence components). In any other situations, where the voltages and currents are composed by distorted or unbalanced components, the instantaneous real power presents average and oscillating components.

The instantaneous zero-sequence power $\left(p_{0}\right)$ results from zero-sequence components of voltages and currents $\left(v_{0}\right.$ and $i_{0}$ ). It is important to comment that this power only exists in three-phase circuits with neutral wire. The average component $\left(\bar{p}_{0}\right)$ corresponds to the energy, per time unity, that flows from the source to the load using the neutral wire. The oscillating component $\left(\tilde{p}_{0}\right)$ corresponds to the energy flow, per time unity, that is exchanged between source and load through the neutral wire. It is important to notice that the average component cannot exist without the presence of the oscillating one [5].

The instantaneous three-phase active power $\left(p_{3 \phi}\right)$, determined directly from the $a-b-c$ phase voltages and line currents, the instantaneous real power $(p)$ and the instantaneous zero-sequence power $\left(p_{0}\right)$, determined in $\alpha-\beta-0$ coordinates, can be correlated as follows:

$$
\begin{aligned}
& p_{3 \phi}=v_{a} i_{a}+v_{b} i_{b}+v_{c} i_{c}= \\
& =v_{\alpha} i_{\alpha}+v_{\beta} i_{\beta}+v_{0} i_{0}=p+p_{0}
\end{aligned} .
$$

In an electrical system where the voltages and currents are only composed by their fundamental positive-sequence components, it is possible to assure that the instantaneous three-phase active power, $p_{3 \phi}$, and the instantaneous real power, $p$, are equal, presenting only average component. Moreover, as described in [5] [13] [14], in this condition it is also possible to affirm that the conventional active power $(P)$ is equal to the instantaneous powers $p_{3 \phi}$ and $p$. In any other conditions, the active power $(P)$ corresponds to the average component of the instantaneous active power $\left(p_{3}\right)$.

The instantaneous imaginary power $(q)$ can be understood as responsible for the energy, per time unit, that is being exchanged between the three-phase wires of the electrical system. Therefore, the power that flows in each phase and depends on $q$ does not contribute to the energy that flows from the source to the load or vice-versa in any time instant. The instantaneous three-phase reactive power $\left(q_{3 \phi}\right)$, determined directly from $a-b-c$ phase voltages and currents, and the imaginary power can be associated as follows:

$$
\begin{aligned}
& q_{3 \phi}=\left(v_{a}-v_{b}\right) i_{c}+\left(v_{b}-v_{c}\right) i_{a}+ \\
& +\left(v_{c}-v_{a}\right) i_{b}=\sqrt{3}\left(v_{\beta} i_{\alpha}-v_{\alpha} i_{\beta}\right)=\sqrt{3} q
\end{aligned}
$$

The instantaneous reactive power $\left(q_{3 \phi}\right)$ is similar to the conventional reactive power $(Q)$ only when just the fundamental positive-sequence (or only negative-sequence) components of the voltages and currents are considered. When the currents or voltages present harmonic or unbalanced components, the instantaneous reactive power, $q_{3 \phi}$, contains average and oscillating components, which makes impossible to compare it directly with $Q$.

Based on the aforementioned explanations involving the instantaneous real, imaginary and zero-sequence powers, it is possible to conclude that:

- The total energy that flows per time unity, that is, the instantaneous three-phase active power, $p_{3 \phi}$, is always equal to the sum of the instantaneous real, $p$, and zero-sequence, $p_{0}$, powers.

- In three-phase circuits, with or without neutral wire, it is possible to affirm that the instantaneous three-phase active power $\left(p_{3 \phi}\right)$ is equal to the conventional active power $(P)$, if the voltages and currents comprises only the fundamental positive-sequence (or only negative-sequence) components.

- The instantaneous imaginary power, $q$, is only derived from the non-homopolar components of the voltages and currents. Moreover, there is a power in each phase that depends on the imaginary power, but their three-phase instantaneous sum is always equal to zero. 
Figure 1 shows the power exchange diagram in a threephase four-wire system. In this figure, the power related to $q$ is shown circulating between the phases $a, b$ and $c$. The real power $p$ and $p_{0}$ represent the energy flow from system $A$ to system $B$ when they are positive. When they are negative, the energy flows from system $B$ to system $A$.

\section{CONTROL AlgORITHM BASED ON THE p-q THEORY FOR SHUNT SWITCHING COMPENSATORS}

One important application of the $p-q$ Theory is the compensation of undesirable current components. Figure 2 illustrates the basic idea of shunt current compensation for a three-phase three-wire system. It shows a source (power generating system) supplying a non-linear load that is being compensated by a shunt compensator. For the sake of simplicity, here it is assumed that the shunt compensator is a three-phase controlled current source that can draw or inject any set of arbitrarily chosen current references $i_{C a}^{*}$, $i_{C b}^{*}$ and $i_{C c}^{*}$, which are in fact the undesirable currentcomponents consumed by the load.

A general control method for shunt current compensation, to be used in the controller of the shunt compensator, is shown in Figure 3. The calculated instantaneous real power, $p$, of the load can be separated in its average $(\underline{p})$ and oscillating $(\tilde{p})$ components. Likewise, the load instantaneous imaginary power, $q$, can be separated in its average $(\underline{q})$ and oscillating $(\widetilde{q})$ components. Then, undesired real and imaginary power-components of the load can be compensated by using adequately designed filters in the block "Selection of the power to be compensated". The powers to be compensated are represented by $-p_{c}^{*}$ and $-q_{c}^{*}$. Note that, the adopted current convention in Figure 2 is such that the source current is the sum of the load current and the compensator current. From $-p_{c}^{*}$ and $-q_{c}^{*}$ it is possible to calculate $i_{\alpha}^{*}$ and $i_{\beta}^{*}$. Then, the inverse transformation from $\alpha-\beta$ to $a-b-c$ is applied to calculate the instantaneous values of the three-phase compensating current references $i_{C a}^{*}, i_{C b}^{*}$ and $i_{C c}^{*}$.

Figure 4 to Figure 8 show various possible compensation results, obtained with the shunt switching compensator of Figure 2 and with the control method of Figure 3 . In all of these cases, the nonlinear load was assumed an ideal (without commutation inductances) three-phase thyristor rectifier, with a constant (no ripple) current source at the dc side. Note that in this type of load there is no current at the neutral wire. Each figure shows the $a$-phase current component that should be eliminated from the load current and the $a$-phase compensated source current, together with the $a$-phase voltage. Furthermore it is also shown the instantaneous real power at source $\left(p_{S}\right)$ and the instantaneous imaginary power at source $\left(q_{S}\right)$. Note that the compensator must produce the inverse of the currentcomponent consumed by the load that must be eliminated. The ideal compensated current can be calculated simply by subtracting the current to be eliminated from the load current. The powers $p_{S}$ and $q_{S}$ correspond to the new instantaneous powers delivered from the source after compensation. In all these cases it is considered that no unbalances or distortions are present in the system voltages.

Figure 4 shows the compensation of the instantaneous imaginary power consumed by the load, $q$, only. In this case, all current components that do not transfer or

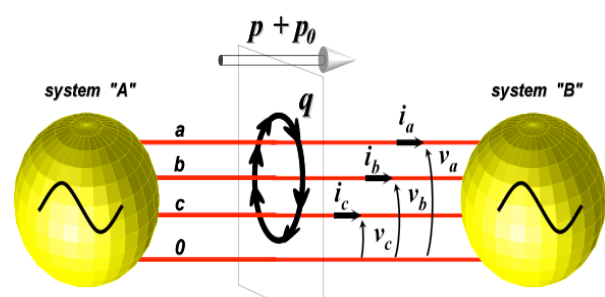

$p+p_{0}:$ instantaneous total energy flow per time unit; Figure 9 : Ponerax exchanaed between the phases without transferring enerast.

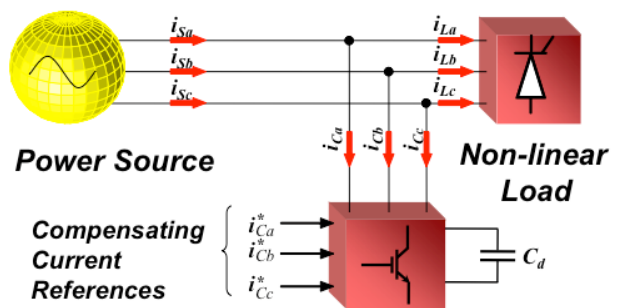

Figure 2. Basic principle of a sGompoevosintorompensator [5].

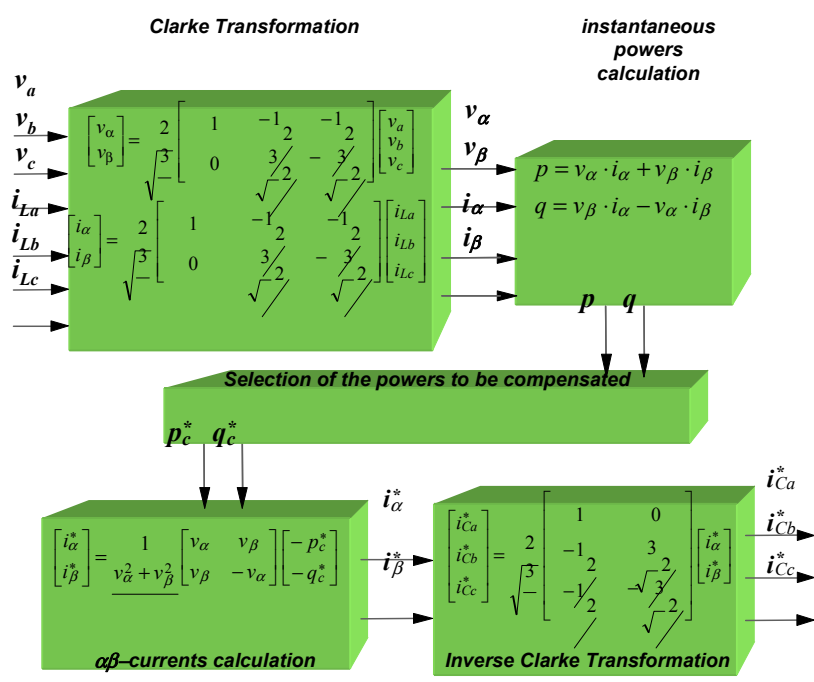

Figure 3. Control method for shunt current compensation based on the p-q Theory [5].

produce losses in the network) are eliminated. Thus, the instantaneous real power at source $\left(p_{S}\right)$ is equal to the instantaneous real power at load $(p)$, while the instantaneous imaginary power at source $\left(q_{s}\right)$ is zero, because it is totally compensated by the shunt switching compensator. One interesting point here is that the shunt compensator, acting as a controlled current sink, draws a compensating current that depends only on $q$, so that no energy is flowing out or into this compensator. This means that, in principle, this compensator does not need any power source or energy storage element. Theoretically, in this case, the capacitor at the DC side of the VSC (Voltage Source Converter) based compensator (Figure 2) could be zero. In actual applications, it is not zero as the switching is done at finite frequency and the synthesized current presents some errors. These errors in the currents implies in small errors in the instantaneous real power at the converter terminals, therefore, forcing the use of a small capacitor in the DC side of the VSC. 
Figure 5 shows the compensation of the average component of the imaginary power consumed by the load, $\bar{q}$, only. In this case, the compensating current, $i_{a \bar{q}}$ (for the $a$-phase), has no harmonic components, and therefore, the shunt compensator draws sinusoidal currents at the line frequency. As expected, the instantaneous real power at source, $p_{S}$, is equal to the instantaneous real power at the load, $p$. The instantaneous imaginary power at the source, $q_{S}$, has only the oscillating component as $\bar{q}_{S}$ is being compensated.

Figure 6 shows the case for the compensation of the load oscillating real power, $\tilde{p}$, only. By taking the currents related to this power as the compensating current reference for the compensator, the instantaneous real power at source, $p_{S}$, becomes constant, without oscillating component. The instantaneous imaginary power at source is the same as that at the load. If the primary power source consists of a turbine generator, this kind of power compensation eliminates the torque ripple in the rotor axis, which may produce undesirable shaft vibration. It is interesting to note that although the compensated current contains significant

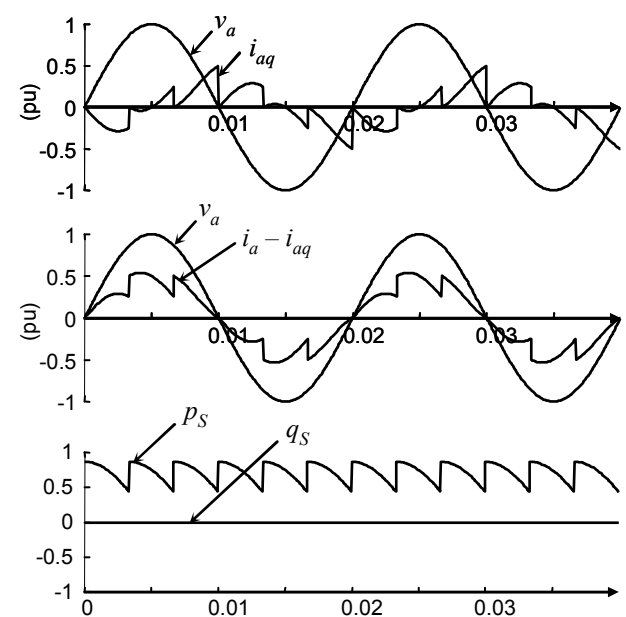

Figure 4. Compensation of the load imaginary power $(q)$ : current to be eliminated $\left(i_{a q}\right)$ and compensated current $\left(i_{a}-i_{a q}\right)$ for the $a$-phase, and the real $\left(p_{S}\right)$ and imaginary $\left(q_{S}\right)$ powers at source [5].

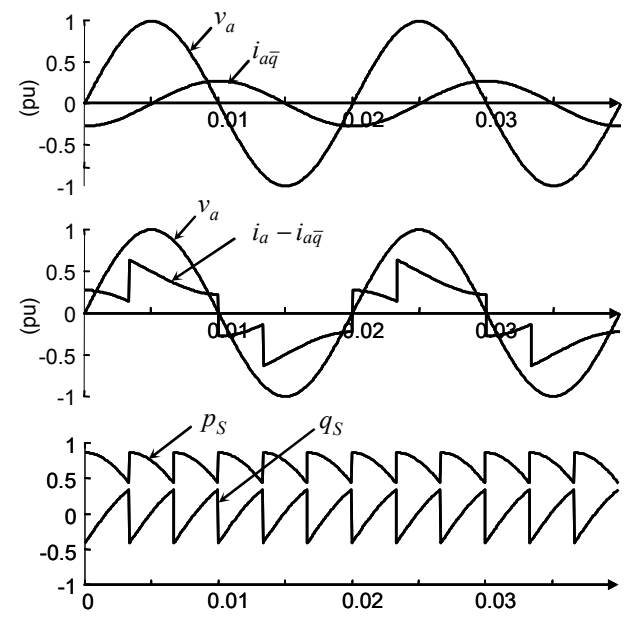

Figure 5. Compensation of the load average imaginary power $(\bar{q})$ : current to be eliminated $\left(i_{a \bar{q}}\right)$ and compensated current $\left(i_{a}-i_{a \bar{q}}\right)$ for the $a$-phase, and the real $\left(p_{S}\right)$ and imaginary $\left(q_{S}\right)$ powers at source [5]. harmonics content, these harmonics do not influence the instantaneous real power. The shunt compensator has to supply exactly the oscillating real power, $\tilde{p}$, that is being eliminated from the power source. Therefore, the compensator must have the capability to supply and absorb energy, but with zero average value. Hence, this compensator must be coupled with an energy storage element, normally a capacitor at the DC side, in the case of compensator based on a VSC (Voltage Source Converter). This type of compensation is important when no oscillating real power is allowed in the source, possibly to avoid mechanical vibrations, including audible noise.

Figure 7 shows the case for compensation of both $\tilde{p}$ and $\tilde{q}$. This kind of compensation is applicable when harmonic elimination is the most important issue. Although the resulting instantaneous real and imaginary powers have no oscillating components, the current related to the average imaginary power, $\bar{q}$, is still flowing in the source, and making the power factor lower than unity. In terms of conventional concepts of powers, the reactive current is not being compensated.

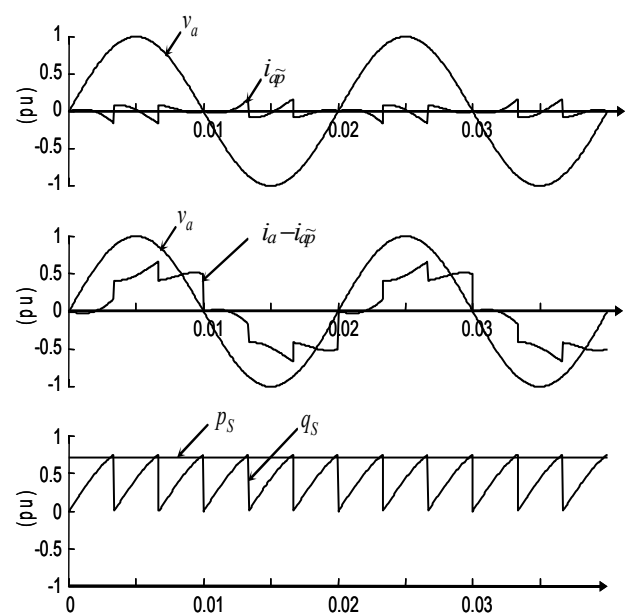

Figure 6. Compensation of the load oscillating real power $(\tilde{p})$ : current to be eliminated ( $\left.i_{a \tilde{p}}\right)$ and compensated current $\left(i_{a}-i_{a \tilde{p}}\right)$ for the $a$ phase, and the real $\left(p_{S}\right)$ and imaginary $\left(q_{S}\right)$ powers at source [5].
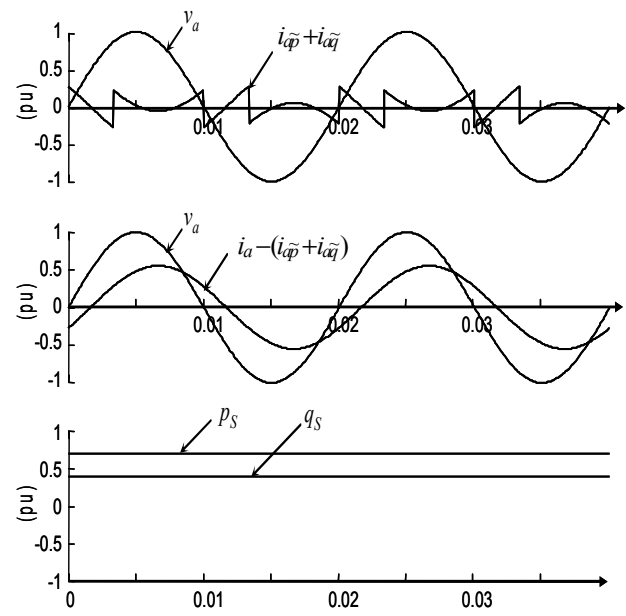

Figure 7. Compensation of $\tilde{p}$ and $\tilde{q}$ : current to be eliminated $\left(i_{a \tilde{p}}+i_{a \tilde{q}}\right)$ and compensated current $\left(i_{a}-\left(i_{a \tilde{p}}+i_{a \tilde{q}}\right)\right)$ for the $a$-phase, and the real $\left(p_{S}\right)$ and imaginary $\left(q_{S}\right)$ powers at source [5]. 


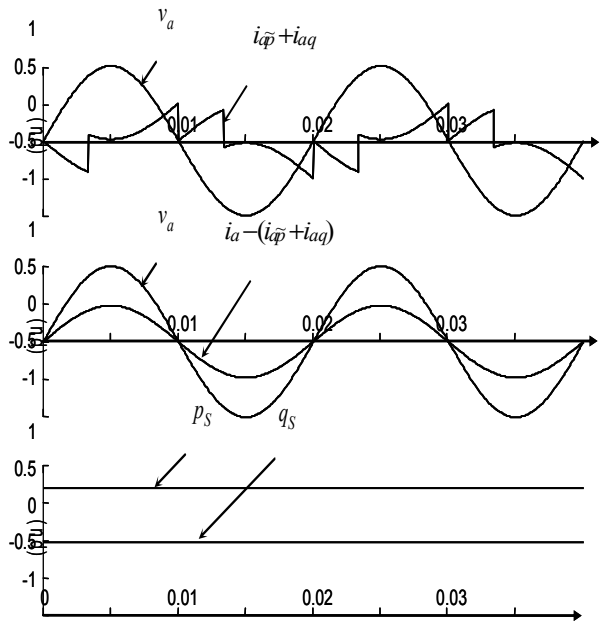

Figure 8. Compensation of $\tilde{p}$ and $q$ : current to be eliminated $\left(i_{a \tilde{p}}+i_{a q}\right)$ and compensated current $\left(i_{a}-\left(i_{a \tilde{p}}+i_{a q}\right)\right)$, and the real $\left(p_{S}\right)$ and imaginary $\left(q_{s}\right)$ powers at source [5].

of $\tilde{p}$ and $q$. Considering that the system voltages are only comprised by their fundamental positive-sequence components, all of the normally considered undesirable current components of the load are eliminated. That is, only active portion of the current at the fundamental frequency is flowing through the source, producing a constant real power, and without imaginary power. Moreover, in this particular case, the non-linear load and the shunt compensator together form an ideal, linear, purely resistive load. The source current has a minimum RMS value that transfers the same energy as the original load current that produce the average real power, $p$. This is the best compensation that can be made from the active power point of view. Besides, it eliminates all harmonic currents. However, it should be pointed out that this is a particular situation where no unbalances or distortions are present in the system voltages.

The compensation examples in Figure 4 to Figure 8 are presented to illustrate clearly all the possibilities of compensation using the $\mathrm{p}-\mathrm{q}$ Theory. These possibilities give a wide flexibility to the active filter design and one can choose which one fits better for each application.

\section{SHUNT COMPENSATOR CONNECTED TO A WEAK ELECTRICAL SYSTEM AND TO A MICRO-GRID}

In this section, it is analyzed the compensation of undesirable currents by a shunt active power compensator connected first to a weak electrical system and then to a micro-grid, both working with a mix of linear and nonlinear, balanced and unbalanced loads. Some cases where the shunt compensator also acts as a voltage regulator, and where there are renewable energy sources injecting energy into the grid are also analyzed.

The electrical system, presented in Figure 9 corresponds to a three-phase $60 \mathrm{kVA}$ four-wire ( 3 phases and neutral wire), $230 \mathrm{~V}$ (phase-to-neutral), $50 \mathrm{~Hz}$ electrical system, with line impedance of $0.2 \mathrm{pu}$. This electrical system feeds different types of loads: Single-Phase Linear Loads (singlephase motors, electrical heaters, incandescent lamps, etc); Single-Phase Non-Linear Loads (TVs, computers, printers, UPS, fluorescent lamps, single-phase motors with adjustable speed drivers, etc); Three-Phase Linear Loads

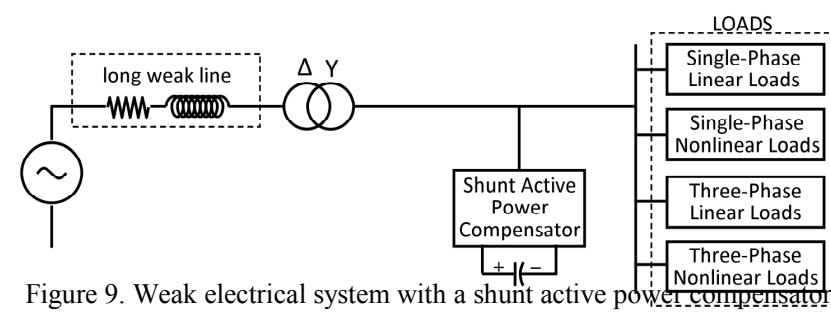

and different types of loads.

(three-phase motors with adjustable speed drivers, threephase UPS). The set of different loads consumes distorted and imbalanced currents, with a high value of neutral current. These currents cause elevated voltage drops in the line impedances of this weak electrical system. Thus, the loads are fed by voltages that are unbalanced, distorted and under nominal values.

\section{CASE 1 - COMPENSATION OF CURRENT HARMONICS, POWER FACTOR AND CURRENT IMBALANCE}

Figure 10 presents the waveforms of voltages and currents in the system shown in Figure 9, as well as the instantaneous value of the three-phase real power $\left(p_{3 \phi}\right)$, with the shunt active power compensator turned-off. As we can observe in Figure 10 (a), the voltage waveforms are highly distorted at the PCC (Point of Common Coupling). The same problem happens with the currents shown in Figure 10 (b). The current in the neutral wire, shown in Figure 10 (c) is also very high and would produce zero sequence power (not shown), because the distorted voltages also present zero sequence components. The instantaneous three-phase real power $\left(p_{3 \phi}\right)$ shown in Figure $10(\mathrm{~d})$ presents a highly oscillating component, which means that the generator axis that produces the electrical energy to feed this electrical system is suffering from torque ripple.

Figure 11 presents the waveforms of voltages and currents, as well as the instantaneous value of the threephase real power, at the system shown in Figure 9, now operating with the shunt active power compensator turnedon. This compensator works with a control system based on the p-q Theory considering the sinusoidal supply current control strategy proposed in [15]. In this strategy, the control system uses the load currents and the fundamental positive-sequence component of the voltages to calculate the power components to be compensated. It is possible to see that, with the operation of the shunt active power compensator, the current harmonics components, the power factor and the current imbalance are totally compensated. Therefore, the source currents only present their fundamental positive-sequence components and, consequently, the neutral current is equal to zero. As a result of that, the voltages turn into sinusoidal and balanced waveforms, and the instantaneous three-phase power becomes constant.

CASE 2 - Voltage REgUlation, COMPENSATION OF CURRENT HARMONICS, POWER FACTOR AND CURRENT IMBALANCE

The shunt active power compensator with the control system based on the p-q Theory also permits to work as a voltage regulator, keeping the voltages at the PCC a the nominal values. This control can be done if the shunt 
(a)

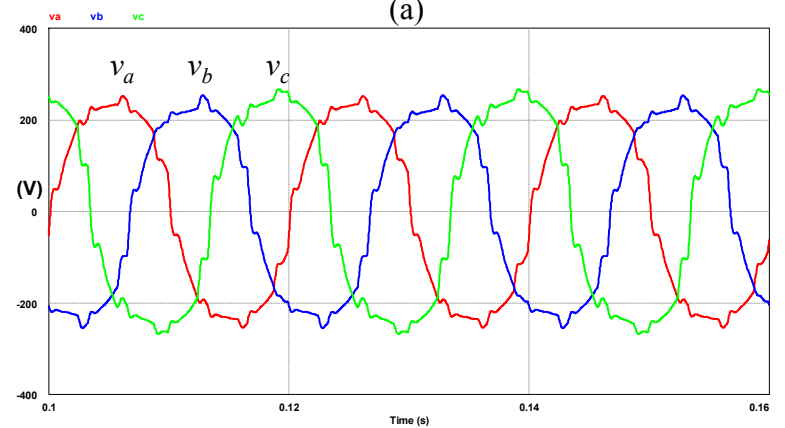

(b)

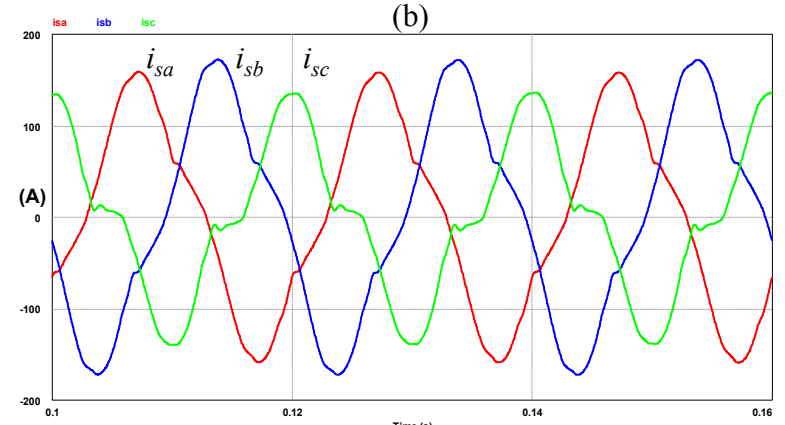

(c)

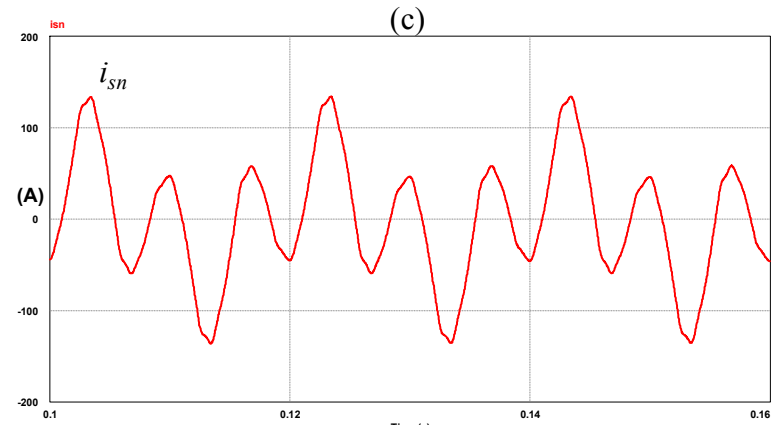

(d)

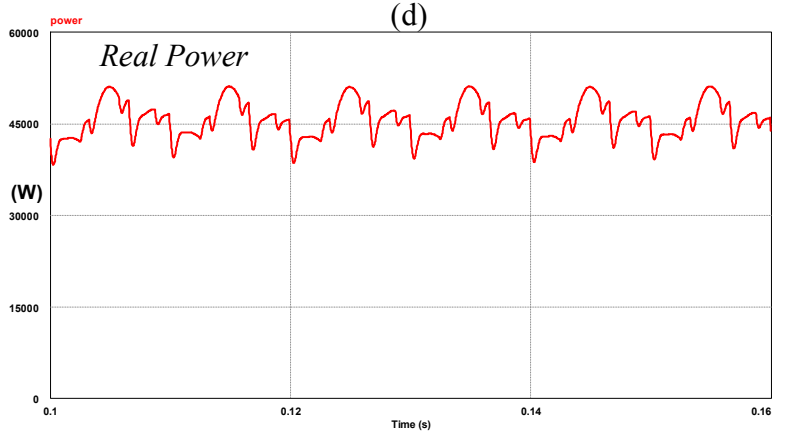

Figure 10. Weak electrical system with the shunt compensator turned-off: (a) System voltages; (b) System current at phases; (c) System neutral current; (d) Instantaneous value of the three-phase real power.

compensator works not only like an active filter, but works also like a STATCOM (static synchronous compensator). In this case, the compensator should be able to produce capacitive or inductive reactive power to increase or decrease the voltage at the PCC. In order to do that, the control system must calculate the reference value for $\bar{q}$ (average value of the instantaneous imaginary power) that is proportional to the overvoltage or undervoltage verified in the PCC.

Figure 12 shows the voltage and current at $a$-phase of the weak electrical system, as well as the RMS value of the voltage at this same phase. It can be seen that, at $t=0.2 \mathrm{~s}$, when the compensator is turned-on only with the function of active filter, the current and the voltage become sinusoidal, and the RMS voltage increases. This increase in (a)

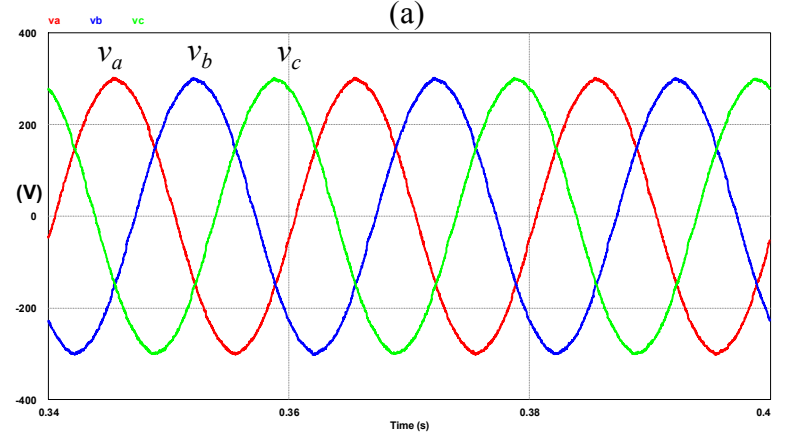

(b)

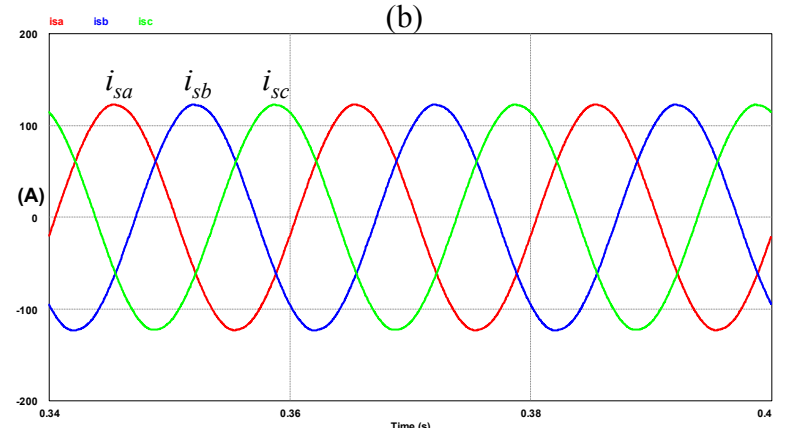

(c)

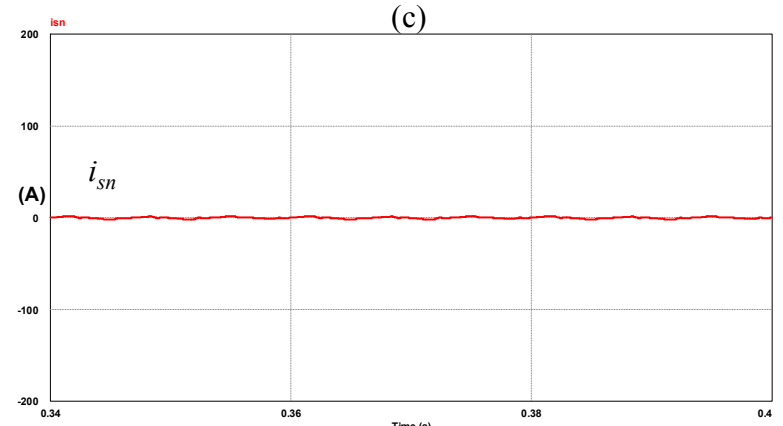

(d)

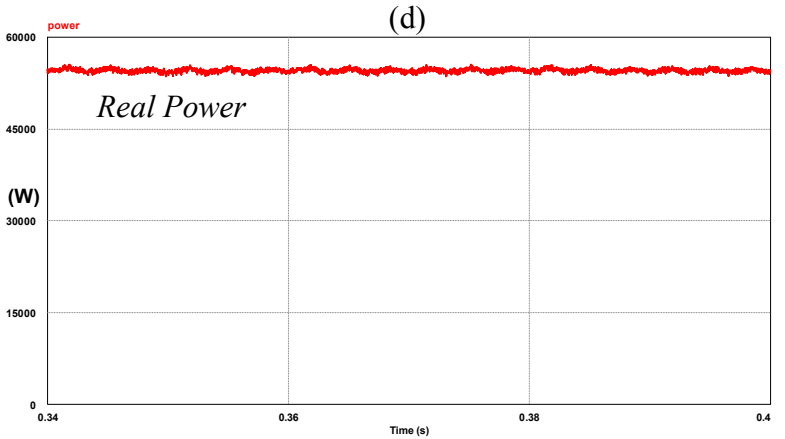

Figure 11. Weak electrical system with the shunt compensator turned-on:

(a) System voltages; (b) System current at phases; (c) System neutral current; (d) Instantaneous value of the three-phase real power.

the voltage occurs because the source current after compensation becomes smaller, and thus the voltage drop at line impedance decreases. At $t=0.3 \mathrm{~s}$, the shunt compensator keeps the operation as an active filter and adds the STATCOM function with the objective of regulating the phase-to-neutral voltage at $230 \mathrm{~V}$. The RMS voltage begins to rise, until it achieves its set point value $(230 \mathrm{~V})$.

CASE 3 - FREQUENCY AND VOlTAGE REgUlation, COMPENSATION OF CURRENT HARMONICS, POWER FACTOR, AND CURRENT IMBALANCE

To show the flexibility of the p-q Theory for frequency control some simulation results are shown considering a very weak micro-grid. 


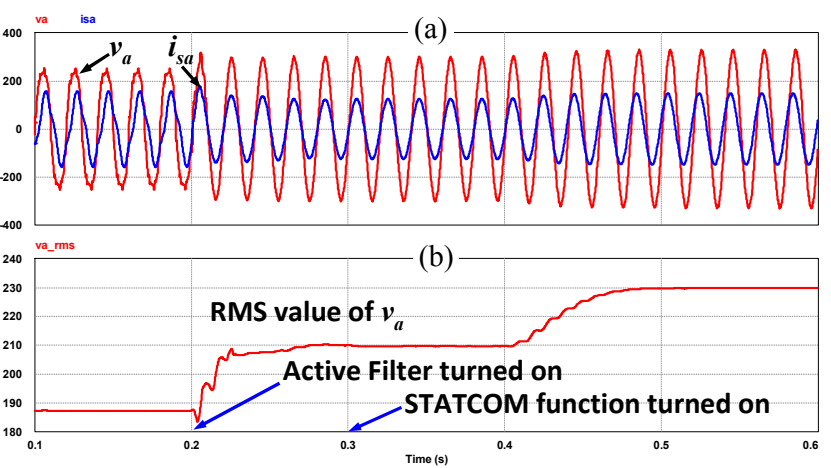

Figure 12. Weak electrical system with the shunt compensator turned-on at $t=0.20 \mathrm{~s}$, and beginning to regulate voltage at $t=0.30 \mathrm{~s}$ (like a STATCOM): (a) Voltage and source current at $a$-phase; (b) RMS value of voltage at $a$-phase.

Figure 13 shows the simulated micro-grid with a combustion engine/synchronous generator as the dispatchable local power source, a wind generator, unbalanced non-linear loads and a shunt active power compensator [7]. It is supposed that the combustion engine/synchronous generator system is able to supply power to the loads, however, whenever possible, the wind generator is controlled to generate maximum power with the objective to save fuel. The load is unbalanced, nonlinear and variable in time. This is a hypothetical situation, however, highly probable to happen in an actual micro-grid. A situation where it is important to have a shunt power compensator to avoid frequency variations will be presented.

Figure 14 shows the instantaneous voltages, currents and frequency in this micro-grid for the steady-state operation (until $t=2.5 \mathrm{~s}$ ). During this time interval, the voltages and currents are distorted and the frequency varies a little bit because the engine/generator system has a very low inertia. During the time interval from $t=2.5 \mathrm{~s}$ to $2.56 \mathrm{~s}$ the load is increased quickly and the frequency varies more than $1 \mathrm{~Hz}$. When this load is disconnected the frequency varies again going up almost $1 \mathrm{~Hz}$.

To avoid this frequency variation in the generator, the shunt compensator should deliver/absorb the transient energy until the generator can take up this power. Knowing the peak value of this energy it is easy to calculate the size of the capacitor to be used in the DC side of the VSC (Voltage Source Converter) of the shunt compensator (in this example a capacitor was chosen as energy storing element), as shown in [9]. Based on this, a shunt compensator was designed to compensate for the oscillating instantaneous real power with a DC capacitor with $50 \mathrm{mF}$ and $860 \mathrm{~V}$. As this capacitor has to absorb energy from or supply energy to the load with a peak value of $650 \mathrm{~J}$, the capacitor voltage may vary $+/-160 \mathrm{~V}$. For larger values of stored energy another energy storing element may have to be used, like double-layer capacitors, flywheel [27], batteries [40], or even SMES.

Energy storage will be another serious problem for future electrical systems. However, they will be necessary if micro-grid and smart grid concepts are to be put in practice. This fact corresponds to the idea of increasing system inertia, not with rotating mass, but with energy storage system and power converter operating as a smart compensator.

Figure 15 shows the simulated voltage, current and frequency for the case that the shunt power compensator is connected and compensating $\tilde{p}$ and $q$. In this case, $\tilde{p}$ was

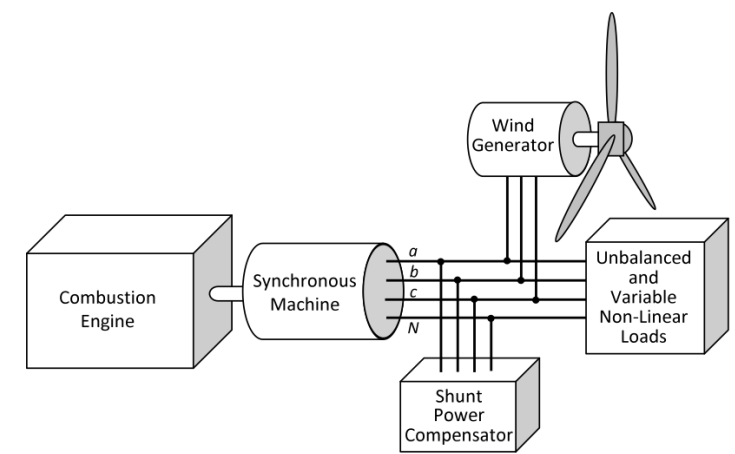

Figure 13. Simulated micro-grid with a combustion engine / generator, wind generator, unbalanced non-linear loads and a shunt compensator [7].

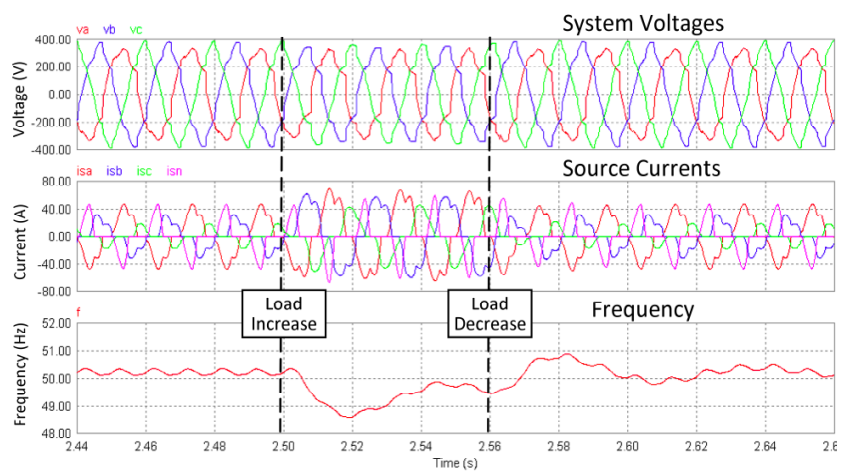

Figure 14.Voltage, current and frequency response for the system without shunt compensator [7].

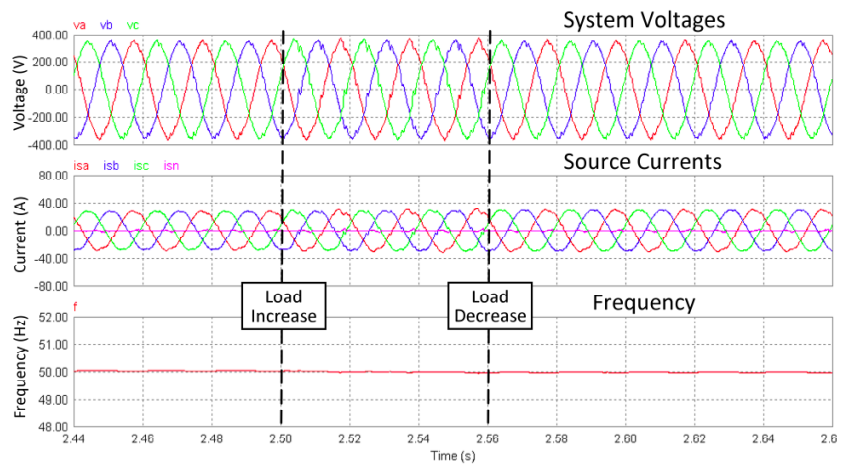

Figure 15. Voltage, current and frequency response for the system with shunt compensator [7]

calculated as $\widetilde{p}=p-\bar{p}$ by using a moving average filter with a time window of 50 cycles for the calculation of the real average power $\bar{p}$. As we can see in this figure, the voltage and current distortion have been greatly reduced and the frequency is now constant. This simple simulation shows that a shunt power compensator can be designed to compensate for oscillating power as in [9] and [10] with the difference that in these references the power supply was running at constant frequency. In a micro-grid the inertia in the electrical system may be too small to keep constant frequency, without the help of a power compensator. It is also possible to see that the compensated current is in phase with the voltage because all the imaginary power is being completely compensated.

The simulation results in this case shows that the $p-q$ Theory can help in designing a power compensator to "add inertia" to the electrical system, with the advantage that this is an inertia with controlled load/unload characteristics. This control is easy to do with this theory because it defines real power considering the three-phase 
voltages and currents. Knowing the value of $\tilde{p}$ that must be compensated, it is easy to design the energy storage system as introduced in [9]. In the others power theories the oscillating real power is not obvious, and therefore it is difficult to adequately know the size of the energy storage element. This is one of the main differences between the $\mathrm{p}-\mathrm{q}$ Theory and the others theories.

\section{CONCLUSiOnS}

This paper presented the p-q Theory and examples emphasizing the physical meaning of each power component. Some important conclusions are given next:

(i) The powers defined in the $p-q$ Theory form a consistent basis for efficient algorithms to be applied in the control of active power conditioners;

(ii) Clear physical meanings are addressed to the real power, the imaginary power, and the zero-sequence power in the $\mathrm{p}-\mathrm{q}$ Theory;

(iii) The compensation algorithm based on the powers defined in the $\alpha-\beta-0$ reference frame is very flexible;

(iv) The undesirable powers to be compensated can be conveniently selected;

(v) The instantaneous imaginary power is calculated without time delay ("instantaneously") and the compensation algorithm using the $\alpha-\beta-0$ transformation can compensate for three-phase loads in order to consume constant instantaneous active power from the source, even if the supply voltages are unbalanced and/or contain harmonics.

This paper presents simulation results that prove that, a shunt active power compensator with the control system based on the p-q Theory can be used in a weak electrical system, or in a micro-grid, in order to compensate for harmonics currents, current imbalance, power factor, and even for voltage distortion, voltage regulation and frequency regulation. In the case of a micro-grid with a weak generator and non-linear unbalanced loads, the $p-q$ Theory allows the precise design of the oscillating real power compensation to avoid frequency variations in systems with low inertia. With this control theory it is also very easy to adequately calculate the size of the energy storage element that is necessary for a shunt active power compensator to compensate the power oscillations, avoiding frequency fluctuations.

\section{REFERENCES}

[1] W. V. Lyon, "Reactive power and unbalanced circuits," Electr. World, vol. 75, no. 25, pp. 1417-1420, 1920.

[2] F. Buchholz, "Die Drehstrom-Scheinleistung bei ungleichmäßiger Belastung der drei Zweige," Licht Kraft, Zeitschrift elekt. EnergieNutzung, no. 2, pp. 9-11, Jan. 1922.

[3] C. I. Budeanu, Puissances Reactives et Fictives. Bucharest, Romania: Instytut Romania de l'Energie, 1927, Pub. no. 2.

[4] H. Akagi, Y. Kanazawa, A. Nabae, "Generalized Theory of the Instantaneous Reactive Power in Three-Phase Circuits," in Proc. IPEC-Tokyo'93 Int. Conf. Power Electronics, pp. 1375-1386, Tokyo, 1983.

[5] H. Akagi, E. H. Watanabe, M. Aredes, Instantaneous Power Theory and Applications to Power Conditioning, New Jersey: IEEE Press Wiley-Interscience, 2007, ISBN: 978-0-470-10761-4. http://www.wiley.com/WileyCDA/WileyTitle/productCd-047011892X.html

[6] E. H. Watanabe, H. Akagi and M. Aredes, "Instantaneous p-q Power Theory for Compensating Nonsinusoidal Systems," International School on Nonsinusoidal Current Compensation (ISNCC 2008), Lagow, Poland, June, 2008.
[7] L. F. C. Monteiro, J. L. Afonso, J. G. Pinto, E. H. Watanabe, M. Aredes and H. Akagi, "Compensation Algorithm Based on the p-q and CPC Theories for Switching Compensators in Micro-Grids," Brazilian Conference on Power Electronics (COBEP 2009), Bonito - MS, Brazil, September, 2009.

[8] H. Akagi, Y. Kanazawa, A. Nabae, "Instantaneous Reactive Power Compensator Comprising Switching Devices Without Energy Storage Components," IEEE Transactions on Industry Applications, vol. IA-20, no. 3, pp. 625-630, 1984.

[9] H. Akagi, A. Nabae and S. Atoh, "Control Strategy of Active Power Filter Using Multiple Voltage Source PWM Converters," IEEE Trans. Ind. Appl., vol. IA-22, no 3, 1986.

[10] E. H. Watanabe and M. Aredes, "Compensation of Non-Periodic Currents Using the Instantaneous Power Theory," IEEE PES Summer Meeting, Seattle, July 2000.

[11] E. H. Watanabe, R. M. Stephan, M. Aredes, "New Concepts of Instantaneous Active and Reactive Powers in Electrical Systems with Generic Loads," IEEE Transactions on Power Delivery, vol. 8, no. 2, pp. 697-703, April 1993.

[12] M. Aredes, E. H. Watanabe, "New Control Algorithms for Series and Shunt Three-Phase Four-Wire Active Power Filters," IEEE Transactions on Power Delivery, vol. 10, no. 3, pp. 1649-1656, July 1995.

[13] M. Aredes, "Active Power Line Conditioners," Ph.D. Thesis, Technische Universität Berlin, Berlin, 1996.

[14] J. L. Afonso, M. J. S. Freitas, J. S. Martins, "p-q Theory Power Components Calculations," 2003 IEEE International Symposium on Industrial Electronics, 2003, vol. 1, pp. 385-390, June 2003, website http://repositorium.sdum.uminho.pt/handle/1822/1864.

[15] J. L. Afonso, C. Couto, J. Martins, "Active Filters with Control Based on the p-q Theory", IEEE Industrial Electronics Society Newsletter, vol. 47, $\mathrm{n}^{\mathrm{o}}$ 3, Sept. 2000, pp. 5-10. http://repositorium.sdum.uminho.pt/handle/1822/1921

[16] P. G. Barbosa, L. G. B. Rolim, E. H. Watanabe, R. Hanitsch, "Control Strategy for Grid-Connected DC-AC with Load Power Factor Correction," IEE Proc. Generation, Transmission and Distribution, vol. 145, pp. 487-491, No. 5, 1998.

[17] M. Depenbrock, "The FBD-Method, a Generally Applicable Tool for Analysing Power Relations," IEEE Transactions on Power Systems, vol. 8, no. 2, pp. 381-387, May 1993.

[18] P. Tenti, E. Tedeschi, P. Mattavelli, "Cooperative Operation of Active Power Filters by Instantaneous Complex Power Control," 7th International Conference on Power Electronics and Drive Systems, 2007 (PEDS '07), pp. 555-561, November 2007.

[19] L. S. Czarnecki, "On some misinterpretations of the instantaneous reactive power $p-q$ theory," IEEE Transactions on Power Electronics, vol. 19, no. 3, pp. 828-836, May 2004.

[20] L. S. Czarnecki, "Instantaneous reactive power $p-q$ theory and power properties of three-phase systems," IEEE Transactions on Power Delivery, vol. 21, no. 1, pp. 362-367, January 2006.

[21] H. S. Kim, H. Akagi, "The instantaneous power theory on the rotating p-q-r reference frames," in Proc. IEEE/PEDS 1999 Conf., Hong Kong, Jul., pp. 422-427.

[22] M. Depenbrock, V. Staudt, H. Wrede, "Concerning instantaneous power compensation in three-phase systems by using $\mathrm{p}-\mathrm{q}-\mathrm{r}$ theory," IEEE Transactions on Power Electronics, vol. 19, no. 4, pp. 11511152, Jul. 2004.

[23] M. Aredes, H. Akagi, E. H. Watanabe, E. V. Salgado, L. F. Encarnação, "Comparisons Between the $p-q$ and $p-q-r$ Theories in Three-Phase Four-Wire Systems," IEEE Transactions on Power Electronics, , vol. 24, no. 4, pp. 924-933, April 2009.

[24] R. I. Bojoi, G. Griva, V. Bostan, M. Guerreiro, F. Farina, F. Profumo, "Current Control Strategy for Power Conditioners Using Sinusoidal Signal Integrators in Synchronous Reference Frame," IEEE Transactions on Power Electronics, vol. 20, no. 6, pp. 1402-1412, November 2005.

[25] I. Van der Hoven, "Power Spectrum of Horizontal Wind Speed in the Frequency Range from 0.0007 to 900 Cycles per Hour," Journal of Meteorology, vol. 14, pp. 160-164, April 1957.

[26] T. Goya et al., Torsional Torque Suppression of Decentralized Generators Based on Hळ Control Theory," International conference on Power System Transient (IPST'2009), Kyoto, 2-6 June 2009.

[27] G. O. Suvire, "Mitigation of Problems Produced by Wind Generators in Weak Systems," Ph.D. Thesis, San Juan National University, Argentina, 2009. (in Spanish).

[28] S. Fryze, "Wirk-, Blind- und Scheinleistung in elektrischen Stromkreisen mit nicht-sinusförmigem Verlauf von Strom und 
Spannung," ETZ-Arch. Elektrotech., vol. 53, pp. 596-599, 625-627, 700-702, 1932.

[29] L. Malesani, L. Rosseto, P. Tenti, “Active Filter for Reactive Power and Harmonics Compensation," Power Electronics Specialist Conference, PESC '86, pp. 321 - 330.

[30] Y. Xu, L. M. Tolbert, J. N. Chiasson, J. B. Campbell, F. Z. Peng, "A generalised instantaneous non-active power theory for STATCOM," IET Electr. Power Appl., 2007, 1, (6), pp. 853-861.

[31] Y. Xu, L. M. Tolbert, F. Z. Peng, J. N. Chiasson, J. Chen, "Compensation-based non-active power definition", IEEE Power Electronics Letters, 2003, 1, (2), pp. 45-50.

[32] F. P. Marafão, S. M. Deckmann, J. A. Pomilio, R. Q. Machado, "Control Strategies to Improve Power Quality," COBEP 2001 - The 6th Brazilian Power Electronics Conf., Florianópolis, pp. 378-383, November 2001

[33] M. Aredes, L. F. C. Monteiro, "Compensation algorithms based on instantaneous powers defined in the phase mode and in the $\alpha \beta 0$ reference frame," COBEP 2003 - Brazilian Power Electronics Conference, Fortaleza, Brazil, pp. 344-349, September 2003.

[34] L. S. Czarnecki, "Current's Physical Components (CPC) in circuits with Nonsinusoidal voltages and currents. Part 2: Three-phase linear circuits," Electrical Power Quality and Utilization Journal, vol. X, no. 1 , pp. 1 - 14, 2006.

[35] L. S. Czarnecki, "Orthogonal decomposition of the currents in a 3 phase nonlinear asymmetrical circuit with a nonsinusoidal voltage source," IEEE Transactions on Instrumentation and Measurement, vol. 37, no. 1, pp. 30 - 34, March 1988.

[36] L. S. Czarnecki, "Reactive and Unbalanced Currents Compensation in Three-Phase Asymmetrical Circuits under Nonsinusoidal Conditions," IEEE Transactions on Instrumentation and Measurement, vol. 38, no. 3, pp. 754 - 759, June 1989.

[37] L. S. Czarnecki, "Scattered and Reactive Current, Voltage, and Power in Circuits with Nonsinusoidal Waveforms and Their Compensation," IEEE Transactions on Instrumentation and Measurement, vol. 40, no. 3, pp. 563 - 567, June 1991.

[38] L. S. Czarnecki, "CPC power theory as control algorithm of switching compensators," Electrical Power Quality and Utilization, $9^{\text {th }}$ International Conference, Barcelona 9-11, October 2007.

[39] E.H. Watanabe, M. Aredes and H. Akagi, "The p-q Theory for Active Filter Control: Some Problems and Solutions", Revista Brasileira de Controle e Automação (SBA), Campinas/SP, Vol. 15, $\mathrm{n}^{\circ}: 01$, pp. 78-84, Jan./Mar. 2004.

[40] H. Akagi and L. Maharjan, "A Battery Energy Storage System Based on a Multilevel Cascade PWM Converter," COBEP2009, Special Session, Bonito, September 2009.

\section{ACKOWLEDGEMENT}

The authors acknowledge the support from FAPERJ partially for the development of this study and especially for the financial support for the participation in the conference.

\section{BIOGRAPHIES}

Edson Hirokazu Watanabe (M'76, SM'02) was born in Rio de Janeiro State, Brazil, on November 07, 1952. He received the Electronic Engineering and master degrees in Electrical Engineering in 1975 and 1976, respectively, from the Federal University of Rio de Janeiro. In 1981, he got the D. Eng. degree from Tokyo Institute of Technology, Japan. In this same year he became an Associate Professor and in 1993 a Professor at COPPE/Federal University of Rio de Janeiro, where he teaches Power Electronics. His main fields of interests are converters analysis, modeling and design, active filters and FACTS technologies. Dr. Watanabe is a member of the IEE-Japan, The Brazilian Society for Automatic Control, The Brazilian Power Electronics Society, CIGRE and Power Engineering, Industry Applications and Power Electronics Societies of IEEE. In 2005 he has admitted to the Order of National Scientific Merit (Brazil). Presently, he is the Academic Director of COPPE/Federal University of Rio de Janeiro.

João Luiz Afonso was born in Rio de Janeiro, Brazil, on May 05, 1963. $\mathrm{He}$ is an Associate Professor at the Department of Industrial Electronics of the University of Minho, Portugal, where he works since 1993. He finished his Engineering course and his MSc at the Federal University of
Rio de Janeiro, Brazil, respectively in 1986 and 1991. He concluded his $\mathrm{PhD}$ in Industrial Electronics at the University of Minho in $2000 \mathrm{He}$ lectures the subjects of Electrical Machines, Complements of Power Electronics, Power Quality, Active Power Filters, and Renewable Energy. His researching activities are related with the Development of Active Power Filters, Power Quality Monitoring Systems, Power Electronics for Renewable Energy Sources and for Electric Vehicles, and with the realization of studies on Power Quality and Energy Efficiency.

José Gabriel Pinto received the degree in Industrial Electronics Engineering and the M.Sc. degree in Industrial Electronics from the Minho University, Guimarães, Portugal, in 2001 and 2004, respectively. From 2002 to 2006 worked as invited assistant at the Electrical Department of the Polytechnic Institute of Bragança. Since 2006, works as investigator at the Energy and Power Electronics group of the Industrial Electronics Department of the Minho University. Actually he is a PhD scholarship in Industrial Electronics Department of the Minho University.

Luís Fernando Corrêa Monteiro was born in Rio de Janeiro, Brazil, on March 1975. He graduated in Electrical Engineering, from the Federal University of Rio de Janeiro (UFRJ) in 2002. In 2003 and 2008 received from the same university (UFRJ) the M.Sc. and Ph.D degrees, respectively. From 2006 to 2008 have developed researchers on his Ph.D. thesis at University of Minho (Portugal). His current research interests include custom power devices, multilevel converters and real-time control algorithms. Dr. Monteiro is a member of the Institute of Electrical Engineers and of the Brazilian Power Electronics Society.

Maurício Aredes (S'94, M'97) was born in 1961. He received the B.Sc. degree from Fluminense Federal University, Rio de Janeiro State in 1984, the M.Sc. degree in Electrical Engineering from Federal University of Rio de Janeiro in 1991, and the Dr.-Ing. degree (cum laude) from Technische Universität Berlin in 1996. From 1985 to 1997 he worked in some major projects and within CEPEL - Centro de Pesquisas de Energia Elétrica, Rio de Janeiro, as R\&D Engineer. In 1997, he became an Associate Professor at the Federal University of Rio de Janeiro, where he teaches Power Electronics. His main research area includes HVDC and FACTS systems, active filters, Custom Power and Power Quality Issues

Hirofumi Akagi (M'87-SM'94-F'96) was born in Okayama, Japan, on 19th August 1951. He received the B.S. degree from the Nagoya Institute of Technology, Nagoya, Japan, in 1974, and the M.Sc. and Ph.D. degrees from the Tokyo Institute of Technology, Tokyo, Japan, in 1976 and 1979, respectively. In 1979, he was with the Nagaoka University of Technology, Nagaoka, Japan, as an Assistant and then Associate Professor in the department of electrical engineering. In 1987, he was a Visiting Scientist at the Massachusetts Institute of Technology for ten months. From 1991 to 1999 , he was a Professor in the department of electrical engineering at Okayama University, Okayama, Japan. From March to August of 1996, he was a Visiting Professor at the University of Wisconsin, Madison and then the Massachusetts Institute of Technology. Since January 2000, he has been a Professor in the department of electrical and electronic engineering at the Tokyo Institute of Technology, Tokyo, Japan.

His research interests include power conversion systems, ac motor drives, active and passive EMI filters, high-frequency resonant inverters for induction heating and corona discharge treatment processes and utility applications of power electronics such as active filters for power conditioning, self-commutated BTB systems, and FACTS devices. He has authored or coauthored some 70 IEEE Journal papers, including two invited papers in Proceedings of the IEEE in 2001 and 2005. According to Google Scholar, the total citation index for all his papers is more than 9,600. He has made presentations many times as a keynote or invited speaker internationally. Since January 2007, he has been the President of the IEEE Power Electronics Society (PELS). He was elected as a Fellow of the IEEE in 1996, and a Distinguished Lecturer of the IEEE Industry Applications Society (IAS) and PELS for 1998-1999. He received two IEEE IAS Transactions Prize Paper Awards in 1991 and 2004, and two IEEE PELS Transactions Prize Paper Awards in 1999 and in 2003, nine IEEE IAS Committee Prize Paper Awards, the 2001 IEEE William E. Newell Power Electronics Award, and the 2004 IEEE IAS Outstanding Achievement Award. He is a recipient of the 2008 IEEE Richard H. Kaufmann Technical Field Award with the following citation: "For pioneering contributions to the theory of instantaneous reactive power ion three-phase circuits and it applications to power conditioning. 